\title{
Syarat Perlu dan Syarat Cukup Submodul Pure pada Modul Perkalian
}

\author{
Astrid A. Titahena, Yopi A. Lesnussa, E. R. Persulessy, D. Patty \\ Jurusan Matematika FMIPA, Universitas Pattimura \\ titahenaacit@gmail.com, yopi_a_lesnussa@yahoo.com, \\ er.persulessy@staff.unpatti.id,pattydyana@gmail.com
}

\begin{abstract}
Abstrak
Modul merupakan suatu struktur aljabar yang dibentuk dari operasi pergandaan skalar antara suatu grup abelian $M$ dan $\operatorname{ring} R$. Jika untuk setiap submodul $N$ di $M$ terdapat ideal presentasi $I \subseteq R$ sedemikian hingga $N=I M$, maka $M$ disebut modul perkalian. Selanjutnya, $N$ dikatakan mempunyai ideal presentasi jika dan hanya jika $M$ adalah modul perkalian. Jika untuk setiap ideal presentasi $I$ dari submodul $N$ memenuhi $I N=N \cap I M$, maka submodul $N$ disebut submodul pure. Tujuan penulisan ini adalah untuk mengkaji kapan suatu submodul $N$ dari $M$ modul perkalian merupakan submodul pure. Lebih lanjut akan dijelaskan beberapa karakteristik suatu submodul pure dari $M$ modul perkalian.

Kata kunci: ideal presentasi, modul, modul perkalian, submodul, pure submodul, submodul perkalian.
\end{abstract}

\begin{abstract}
The module is an algebraic structure that is formed by scalar multiplication between an abelian Group $M$ and the ring $R$. If for any submodules $N$ in $M$ there are ideal presentation $I \subseteq R$ such that $N=I M$, then $M$ is called the multiplication module. Furthermore, the submodule $N$ is said to have the ideal presentation if and only if $M$ is a multiplication module. If for any ideal presentation I of submodules $N$ occured $I N=N \cap I M$, then $N$ is called a pure submodule. In this paper obtained a submodules $N$ of $M$ in pure submodule if and only if $N$ multiplication submodule and idempotent in $M$.
\end{abstract}

Keywords :ideal presentation, module, module multiplication, submodule, pure submodule, multiplication submodule

\section{Pendahuluan}

Modul merupakan perumuman dari ruang vektor, dikarenakan struktur lapangan pada ruang vektor diperumum menjadi ring. Sehingga, jika pada ruang vektor skalarnya merupakan elemen di lapangan maka pada modul skalarnya merupakan elemen di ring. Diberikan suatu grup abelian $M$ dan ring $R . M$ disebut modul atas ring $R$ jika $M$ merupakan modul kiri sekaligus juga modul kanan (lihat [10]). Dengan demikian, pada tulisan ini ring yang dimaksudkan adalah ring komutatif dengan elemen satuan, sehingga modul $M$ disebut modul unital atas $\operatorname{ring} R$ dan selanjutnya dinotasikan dengan $R$-modul $M$.

2000 Mathematics Subject Classification: 06F25

Received: 2018-08-15, accepted: 2018-11-20 
106 Titahena dkk, JMI Vol 14 No 2 Okt 2018, pp. 105-112,doi:10.24198/jmi.v14.n2.2018.105-112

Seperti halnya subring dan ideal pada ring, terdapat juga struktur submodul dan ideal presentasi pada modul. Suatu $R$-modul $M$ disebut modul perkalian jika terdapat ideal $I$ di ring $R$ sedemikian hingga $N=I M$, untuk setiap submodul $N$ di $R$-modul $M$. Ideal $I$ kemudian disebut sebagai ideal presentasi dari submodul $N$. Selanjutnya, suatu submodul $N$ dari $R$ modul $M$ disebut submodul pure jika untuk setiap ideal presentasi $I$ berlaku $I N=N \cap I M$ (lihat [3]).

Dalam tulisan ini dibahas beberapa syarat perlu dan syarat cukup submodul pure pada modul perkalian terkait dengan submodul pure yang merupakan submodul perkalian dan sifat idempotennya pada modul yang merujuk pada jurnal Pure Submodules of Multiplication Modules (lihat [1]).

\section{LANDASAN TEORI}

Berikut merupakan definisi dari annihilator pada modul yang merupakan landasan dalam penulisan ini, dengan rujukan utama [3],[8],[9].

Definisi 2.1. [3] Diberikan $R$-modul $M$. Annihilator dari $R$-modul $M$ adalah himpunan $\{r \in$ $R \mid r m=0, \forall m \in M\}$ dan dinotasikan dengan $A_{n} n_{R}(M)$. Dengan kata lain Ann $_{R}(M)=\{r \in$ $R \mid r m=0, \forall m \in M\}$.

Untuk sebarang submodul $K$ dalam $R$-modul $M$, didefinisikan himpunan $[K: M]=\{r \in$ $R \mid r M \subseteq K\}$. Himpunan $[K: M]$ merupakan annihilator dalam modul faktor $M / K$ atas ring $R$ (notasinya $R$-modul $(M / K))$.

Contoh 2.2. Annihilator di $\mathbb{Z}$-modul $\mathbb{Z}_{6}$ adalah $6 \mathbb{Z}$. Jika diberikan $\mathbb{Z}_{6}$ adalah $\mathbb{Z}$-modul dengan $\mathbb{Z}_{6}=\{0,1,2,3,4,5\}$ maka himpunan $\operatorname{Ann}\left(\mathbb{Z}_{6}\right)$ adalah

$$
\begin{aligned}
\operatorname{Ann}\left(\mathbb{Z}_{6}\right) & =\left\{z \in \mathbb{Z} \mid z m=0, \forall m \in \mathbb{Z}_{6}\right\} \\
& =\{0, \pm 6, \pm 12, \pm 18, \ldots\} \\
& =6 \mathbb{Z}
\end{aligned}
$$

Lemma-lemma berikut merupakan lemma yang menjelaskan hubungan antara modul dengan annihilator.

Lemma 2.3. [3] Jika $R$ adalah ring komutatif dan $M$ adalah $R$-modul $M$ maka $A n n_{R}(M)$ merupakan ideal (kiri dan kanan) di ring $R$

Bukti.

(1) Jelas bahwa $A n n_{R}(M) \neq \varnothing$ karena terdapat $0 \in A n n_{R}(M)$ sehingga berlaku $0 . m=0$, $\forall m \in M$.

(2) Ambil sebarang $r_{1}, r_{2} \in A n n_{R}(M)$ dan $r \in R$ artinya $r_{1} m=0$ dan $r_{2} m=0$, untuk setiap $m \in M$.

Akan ditunjukkan $r_{1}-r_{2} \in A n n_{R}(M)$. Diperhatikan bahwa $\left(r_{1}-r_{2}\right) m=r_{1} m-r_{2} m=$ $0-0=0$

Dari sini $\left(r_{1}-r_{2}\right) m=0$ atau dengan kata lain $r_{1}-r_{2} \in A n n_{R}(M)$.

(3) Ambil sebarang $r_{1} \in A n n_{R}(M)$ dan $r \in R$. Akan ditunjukkan $r_{1} r \in A n n_{R}(M)$. Diperhatikan bahwa $\left(r_{1} r\right) m=\left(r r_{1}\right) m=r\left(r_{1} m\right)=r .0=0$, untuk suatu $m \in M$. Jadi, $r_{1} r \in A n n_{R}(M)$. Selanjutnya akan ditunjukkan $r r_{1} \in A n n_{R}(M)$. Diperhatikan bahwa $\left(r r_{1}\right) m=r\left(r_{1} m\right)=r .0=0$. Jadi, $r r_{1} \in A n n_{R}(M)$.

Dari penjelasan di atas terbukti bahwa $A n n_{R}(M)$ merupakan ideal di $\operatorname{ring} R$.

Lemma 2.4. [3] Jika $M$ adalah $R$-modul dan $N$ adalah submodul, maka $[N: M]=\{r \in$ $R \mid r M \subseteq N\}$ adalah ideal di ring $R$. 
Bukti. Akan dibuktikan [N:M] adalah ideal.

(1) Ambil sebarang $a, b \in[N: M]$ artinya $a M \subseteq N$ dan $b M \subseteq N$. Akan ditunjukkan $a-b \in[N: M]$. Karena $a M \subseteq N$ dan $b M \subseteq N$ sehingga $(a-b) M=a M-b M \subseteq N$. Dari sini diperoleh $(a-b) M \subseteq N$ atau dengan kata lain $a-b \in(N: M)$.

(2) Ambil sebarang $a \in[N: M]$ artinya $a M \subseteq N$ dan diambil $r \in R$. Karena $a M \subseteq N$ maka $(r a) M=r(a M) \subseteq N$. Dari sini diperoleh $(r a) M \subseteq N$ atau dengan kata lain $r a \in[N: M]$ Sehingga $r a \subseteq[N: M]$.

Terbukti bahwa himpunan $[N: M]$ merupakan ideal di ring $R$.

\section{Hasil Dan Pembahasan}

Dalam teori ring dan teori modul telah diketahui bahwa himpunan $n \mathbb{Z}$ merupakan ideal di $\operatorname{ring} \mathbb{Z}$ (lihat $[6]$ ) sekaligus juga merupakan submodul pada $\mathbb{Z}$-modul $\mathbb{Z}$. Selanjutnya dibentuk operasi pergandaan skalar antara ideal $n \mathbb{Z}$ dengan modul $\mathbb{Z}$ yang membentuk submodul $n \mathbb{Z}$ sebagai berikut $\circ: n \mathbb{Z} \times \mathbb{Z} \rightarrow n \mathbb{Z}$.

Selanjutnya didefinisikan modul perkalian merujuk pada [4].

Definisi 3.1. Suatu $R$-modul $M$ disebut modul perkalian jika untuk setiap submodul $N$ di $M$ terdapat ideal $I$ di $R$ sedemikian sehingga $N=I M$. Dapat juga ditulis $I=[N: M]=\{r \in$ $R \mid r M \subseteq N\}$.

Untuk memperjelas Definisi 3.1 diberikan contoh berikut.

Contoh 3.2. Modul $\mathbb{Z}$ atas ring $\mathbb{Z}$ merupakan modul perkalian.

Akan ditunjukkan terlebih dahulu bahwa $N=n \mathbb{Z}$ merupakan submodul di $\mathbb{Z}$-modul $\mathbb{Z}$ dengan menggunakan teorema submodul (lihat [7]) yaitu jika diberikan $M R$-modul dan himpunan tak kosong $S \subseteq M$. Himpunan $S$ merupakan submodul di $M$ jika dan hanya jika memenuhi sifat:

(1) $\left(\forall s_{1}, s_{2} \in S\right) s_{1}-s_{2} \in S$

(2) $(\forall r \in R)(\forall s \in S) r s \in S$

Selanjutnya,

(1) Jelas bahwa $n \mathbb{Z} \neq \emptyset$ karena ada $0=n .0=n \mathbb{Z}, 0 \in Z$.

(2) Akan ditunjukkan $x-y \in n \mathbb{Z}$. Ambil sebarang $x, y \in n \mathbb{Z}$ artinya $x=n z_{1}$ dan $y=n z_{2}$, untuk setiap $z_{1}, z_{2} \in \mathbb{Z}$. Diperhatikan bahwa $x-y=n z_{1}-n z_{2}=n\left(z_{1}-z_{2}\right)=n z_{3}$, dengan $z_{3}=z_{1}-z_{2} \in \mathbb{Z}$. Dari sini diperoleh $x-y \in n \mathbb{Z}$.

(3) Akan ditunjukkan $r x \in n \mathbb{Z}$. Ambil sebarang $r \in R$ dan $x \in n \mathbb{Z}$ artinya $x=n z_{1}$, untuk suatu $z_{1} \in \mathbb{Z}$. Diperhatikan bahwa $r x=r\left(n z_{1}\right)=n\left(r z_{1}\right)=n z_{4}$, dengan $z_{4}=r z_{1} \in \mathbb{Z}$. Dari sini diperoleh $r x \in n \mathbb{Z}$.

Jadi terbukti $n \mathbb{Z}$ merupakan submodul di $Z$-modul $Z$.

Selanjutnya akan ditunjukkan bahwa himpunan $\mathbb{Z}$ adalah $\mathbb{Z}$-modul perkalian yaitu untuk setiap submodul $n \mathbb{Z}$ di $\mathbb{Z}$-modul $\mathbb{Z}$ akan ditunjukkan terdapat ideal $n \mathbb{Z}$ di ring $\mathbb{Z}$ sedemikian sehingga $n \mathbb{Z}=(n \mathbb{Z}) \mathbb{Z}$.

(1) Akan ditunjukkan $n \mathbb{Z} \subseteq(n \mathbb{Z}) \mathbb{Z}$

Sebarang na $\subseteq n \mathbb{Z}$, untuk setiap $a \subseteq Z$ dapat dinyatakan dalam $n a=\left(n 1_{Z}\right) a \in(n \mathbb{Z}) \mathbb{Z}$ sehingga cukup jelas bahwa $n \mathbb{Z} \subseteq(n \mathbb{Z}) \mathbb{Z}$.

(2) Akan ditunjukkan $(n \mathbb{Z}) \mathbb{Z} \subseteq n \mathbb{Z}$

Sebarang $(n a) b \subseteq(n \mathbb{Z}) \mathbb{Z}$ untuk setiap $a, b \in \mathbb{Z}$ dapat dinyatakan dalam $(n a) b=n(a b)=$ $n c \subseteq n \mathbb{Z}$ untuk suatu $a b=c \in \mathbb{Z}$ sehingga cukup jelas $(n \mathbb{Z}) \mathbb{Z} \subseteq n \mathbb{Z}$.

Dengan demikian terbukti bahwa $\mathbb{Z}$ adalah $\mathbb{Z}$-modul perkalian karena untuk setiap submodul $n \mathbb{Z}$ di $\mathbb{Z}$-modul $\mathbb{Z}$ terdapat ideal $n \mathbb{Z}$ di ring $\mathbb{Z}$ sehingga $n \mathbb{Z}=(n \mathbb{Z}) \mathbb{Z}$.

Lemma berikut merupakan syarat perlu dan syarat cukup suatu modul perkalian. 
108 Titahena dkk, JMI Vol 14 No 2 Okt 2018, pp. 105-112,doi:10.24198/jmi.v14.n2.2018.105-112

Lemma 3.3. [4] Diberikan ring $R$ dan $M$ adalah $R$-modul. Modul $M$ disebut modul perkalian atas $R$ jika dan hanya jika untuk setiap $N$ submodul di $M$ berlaku $N=[N: M] M=\{r \in$ $R \mid(r M) M \subseteq N\}$.

Bukti. $(\Longrightarrow)$ Diketahui $M$ adalah modul perkalian atas $R$. Akan ditunjukkan untuk setiap submodul $N$ di $M$ berlaku $N=[N: M] M$. Hal ini berarti harus ditunjukkan bahwa $N \subseteq[N$ : $M] M$ dan $[N: M] M \subseteq N$.

(1) $N \subseteq[N: M] M$

Ambil sebarang $n \in N$. Karena $M$ adalah modul perkalian berarti untuk setiap $N$ submodul di $M$ terdapat ideal $I$ di $R$ sedemikian sehingga $N=I M$ atau $n$ dapat dinyatakan sebagai $n=r m$, dengan $r \in I, m \in M$. Selanjutnya, karena $r \in I$ dan berdasarkan Definisi 3.1 yaitu $I \subseteq[N: M]$ maka $r \in[N: M]$. Karena untuk setiap $m \in M$ berlaku $r m \in I M=N$ diperoleh $n=r m \in[N: M] M$.

Terbukti $N \subseteq[N: M] M$.

(2) $[N: M] M \subseteq N$ Ambil sebarang $x \in[N: M] M$ artinya $x$ dapat dinyatakan sebagai $x=r m$, dengan $r \in[N: M]$ dan $m \in M$. Karena $r \in[N: M]$ maka berlaku $r M \subseteq N$ yang artinya $r m \subseteq N$, sehingga $x=r m \in N$.

Terbukti $[N: M] M \subseteq N$.

Karena $N \subseteq[N: M] M$ dan $[N: M] M \subseteq N$ maka $N=[N: M] M$, untuk setiap submodul $N$ di $M$.

$(\Longleftarrow)$ Diketahui untuk setiap submodul $N$ di $M$ berlaku $N=[N: M] M=\{r \in R \mid(r M) M \subseteq$ $N\}$. Akan ditunjukkan $M$ adalah modul perkalian yang berarti untuk setiap submodul $N$ di $M$ terdapat ideal $I$ di ring $R$ yang memenuhi $N=I M$. Hal ini berarti harus ditunjukkan bahwa $N \subseteq I M$ dan $I M \subseteq N$

(1) $N \subseteq I M$

Ambil sebarang $n \in N$. Karena $N=[N: M] M$ diperoleh $n \in[N: M] M$. Selanjutnya, berdasarkan Definisi 3.1 yaitu $[N: M] \subseteq I$ maka $n \in I M$. Terbukti $N \subseteq I M$.

(2) $I M \subseteq N$

Ambil sebarang $x \in I M$ berarti $x$ dapat dinyatakan dengan $x=r m$, dengan $r \in I$ dan $m \in M$. Karena $r \in I$ dan $I \subseteq[N: M]$ maka $r \in[N: M]$ sehingga $x=r m \in[N$ : $M] M$. Selanjutnya, untuk setiap submodul $N$ di $M$ berlaku $N=[N: M] M$ maka $x=r m \in N$. Terbukti $I M \subseteq N$.

Karena $N \subseteq I M$ dan $I M \subseteq N$ maka $N=I M$ atau dapat dikatakan bahwa $M$ merupakan modul perkalian. Berdasarkan Definisi 3.1 dan Lemma 3.3, terbukti bahwa jika $M$ adalah modul perkalian dan $N$ submodul dari $M$ maka $N$ dapat dinyatakan dengan $N=I M=[N$ : $M] M$.

Lemma berikut merupakan landasan pembentukan submodul perkalian.

Lemma 3.4. [7] Diberikan $A$ dan $B$ adalah $R$-modul. Jika $B$ adalah modul perkalian maka $A \cap B=[A B] B$.

Bukti. Diberikan modul perkalian $B$ berarti untuk setiap submodul $N$ di $B$ terdapat ideal $I$ sehingga $N=I B$. Akan ditunjukkan $A \cap B=[A: B] B$ yang berarti harus ditunjukkan bahwa $A \cap B \subseteq[A: B] B$ dan $[A: B] B \subseteq A \cap B$.

(1) $A \cap B \subseteq[A: B] B$

Ambil sebarang $x \in A \cap B$ yang berarti $x \in A$ dan $x \in B$. Akan ditunjukkan $x \in$ $[A: B] B$. Karena $x \in B$ dan $B$ modul perkalian yang berarti terdapat ideal $I$ di $R$ sehingga $x \in I B$. Selanjutnya, karena $[A: B] \subseteq I$ maka $x \in[A: B] B$.

Terbukti $A \cap B \subseteq[A: B] B$.

(2) $[A: B] B \subseteq A \cap B$

Ambil sebarang $x \in[A: B] B$ artinya $x=r b$ dengan $r \in[A: B]$ dan $b \in B$. Akan ditunjukkan $x \in A \cap B$. Untuk $r \in[A: B]$ artinya $r B \subseteq A$ atau $r b=a$, untuk suatu 
$a \in A$ sehingga $x=r b \in A$. Selanjutnya, $B$ merupakan $R$-modul sehingga $x=r b \in B$.

Karena $x \in A$ dan $x \in B$ maka $x \in A \cap B$.

Terbukti $[A: B] B \subseteq A \cap B$.

Karena $A \cap B \subseteq[A: B] B$ dan $[A: B] B \subseteq A \cap B$ maka $A \cap B=[A: B] B$. Berdasarkan Lemma 3.4 diperoleh bahwa suatu submodul $N$ di $M$ disebut submodul perkalian di $M$ jika dan hanya jika $K \cap N=[K: N] N$ untuk setiap submodul $K$ di $M$.

Teorema berikut akan digunakan untuk membuktikan Teorema 2 (bagian 2).

Teorema 3.5. Diberikan sebuah ring $R, R$-modul perkalian $M$ dan $K$ submodul di $M$. Jika $[K: M] \subseteq[K: N]$ maka $N \subseteq M$.

Bukti. Ambil sebarang $r \in[K: M]$ berarti $r M \subseteq K, r \in[K: N]$ berarti $r N \subseteq K$ atau $r$ dapat dinyatakan dengan $r m=k$, dengan $m \in M, k \in K$ dan $r n=k$, dengan $n \in N, k \in K$. Karena $r m=r n$ akibatnya berdasarkan hukum kanselasi di modul diperoleh $m=n$. Karena $m=n, m \in M$ maka $n \in M$. Karena $n \in N$ dan $n \in M$ maka diperoleh $N \subseteq M$.

Berikut ini akan dijelaskan definisi submodul pure pada sebarang modul atas ring $R$.

Definisi 3.6. [2] Diberikan $R$ ring dan $M$ adalah $R$-modul. Suatu submodul $N$ di $M$ disebut submodul pure jika $I N=N \cap I M$, untuk setiap $I$ ideal di $R$.

Contoh 3.7. Diberikan $R$ ring, $M$ adalah $R$-modul perkalian dan $N$ submodul di $M$. Suatu jumlahan langsung $N$ di $M$ adalah submodul pure [6].

Bukti. Diketahui $M$ adalah modul perkalian. Akan ditunjukkan $N_{1} \oplus N_{2} \oplus \ldots \oplus N_{k}$ adalah submodule pure yaitu untuk setiap ideal $I$ di $R$ berlaku

$$
I\left(N_{1} \oplus N_{2} \oplus \ldots \oplus N_{k}\right)=\left(N_{1} \oplus N_{2} \oplus \ldots \oplus N_{k}\right) \cap I\left(N_{1}+N_{2}+\ldots+N_{k}\right)
$$

dengan $N_{1}, N_{2}, \ldots, N_{k}$ merupakan submodul-submodul di $M$. Hal ini berarti harus ditunjukkan bahwa:

(1) $I\left(N_{1} \oplus N_{2} \oplus \ldots \oplus N_{k}\right) \subseteq\left(N_{1} \oplus N_{2} \oplus \ldots \oplus N_{k}\right) \cap I\left(N_{1}+N_{2}+\ldots+N_{k}\right)$

(2) $\left(N_{1} \oplus N_{2} \oplus \ldots \oplus N_{k}\right) \cap I\left(N_{1}+N_{2}+\ldots+N_{k}\right) \subseteq I\left(N_{1} \oplus N_{2} \oplus \ldots \oplus N_{k}\right)$

Dalam teori modul, $N_{1} \oplus N_{2} \oplus \ldots \oplus N_{k}=M$ artinya $N_{1}+N_{2}+\ldots+N_{k}=M$ dan $N_{1} \cap N_{2} \cap \ldots \cap N_{k}=$ $\{0\}$.

(1) Ambil sebarang $x \in I\left(N_{1} \oplus N_{2} \oplus \ldots \oplus N_{k}\right)$. Akan ditunjukkan bahwa

$$
x \in\left(N_{1} \oplus N_{2} \oplus \ldots \oplus N_{k}\right) \cap I\left(N_{1}+N_{2}+\ldots+N_{k}\right)
$$

$x \in I\left(N_{1} \oplus N_{2} \oplus \ldots \oplus N_{k}\right)$ berarti $x=r a$, dengan $r \in I$ dan $a \in\left(N_{1} \oplus N_{2} \oplus \ldots \oplus N_{k}\right)$ atau $a=\sum_{i=1}^{k} n_{i}, n_{i} \in N_{i}$. Selanjutnya,

$$
\begin{aligned}
x & =r a \\
& =r\left(\sum_{i=1}^{k} n_{i}\right) \\
& =\sum_{i=1}^{k} r n_{i} \\
& =\sum_{i=1}^{k} n_{j}
\end{aligned}
$$

Sehingga $x \in\left(N_{1} \oplus N_{2} \oplus \ldots \oplus N_{k}\right)$.

Diketahui $M$ modul perkalian berarti terdapat ideal $I$ di $R$ sehingga $\left(N_{1} \oplus N_{2} \oplus \ldots \oplus\right.$ $\left.N_{k}\right)=I\left(N_{1}+N_{2}+\ldots+N_{k}\right)$. Selanjutnya $x \in\left(N_{1} \oplus N_{2} \oplus \ldots \oplus N_{k}\right)$ dan $\left(N_{1} \oplus N_{2} \oplus \ldots \oplus\right.$ $\left.N_{k}\right)=I\left(N_{1}+N_{2}+\ldots+N_{k}\right)$ jadi $x \in I\left(N_{1}+N_{2}+\ldots+N_{k}\right)$. Karena $x \in\left(N_{1} \oplus N_{2} \oplus \ldots \oplus N_{k}\right)$ dan $x \in I\left(N_{1}+N_{2}+\ldots+N_{k}\right)$ berarti $x \in\left(N_{1} \oplus N_{2} \oplus \ldots \oplus N_{k}\right) \cap I\left(N_{1}+N_{2}+\ldots+N_{k}\right)$. Terbukti $I\left(N_{1} \oplus N_{2} \oplus \ldots \oplus N_{k}\right) \subseteq\left(N_{1} \oplus N_{2} \oplus \ldots \oplus N_{k}\right) \cap I\left(N_{1}+N_{2}+\ldots+N_{k}\right)$. 
110 Titahena dkk, JMI Vol 14 No 2 Okt 2018, pp. 105-112,doi:10.24198/jmi.v14.n2.2018.105-112

(2) Ambil sebarang $x \in\left(N_{1} \oplus N_{2} \oplus \ldots \oplus N_{k}\right) \cap I\left(N_{1}+N_{2}+\ldots+N_{k}\right)$ berarti $x \in\left(N_{1} \oplus N_{2} \oplus\right.$ $\left.\ldots \oplus N_{k}\right)$ dan $x \in I\left(N_{1}+N_{2}+\ldots+N_{k}\right)$. Akan ditunjukkan $x \in I\left(N_{1} \oplus N_{2} \oplus \ldots \oplus N_{k}\right)$. Karena $N_{1}+N_{2}+\ldots+N_{k}=M=N_{1} \oplus N_{2} \oplus \ldots \oplus N_{k}$ maka untuk sebarang $x \in$ $I\left(N_{1}+N_{2}+\ldots+N_{k}\right)$ diperoleh $x \in I\left(N_{1} \oplus N_{2} \oplus \ldots \oplus N_{k}\right)$.

Terbukti $\left(N_{1} \oplus N_{2} \oplus \ldots \oplus N_{k}\right) \cap I\left(N_{1}+N_{2}+\ldots+N_{k}\right) \subseteq I\left(N_{1} \oplus N_{2} \oplus \ldots \oplus N_{k}\right)$

Berdasarkan (1) dan (2) terbukti bahwa jumlahan langsung $N$ di $M$ adalah submodul pure.

Berikut ini akan dijelaskan definisi submodul idempoten.

Definisi 3.8. [1] Diberikan ring $R$ dan $R$-modul $M$. Suatu submodul $N$ di $M$ disebut submodul idempoten jika dan hanya jika $N=[N: M] N$.

Teorema 3.9. [2] Diberikan ring $R$ dan $M$ adalah $R$-modul perkalian. Jika $N$ adalah submodul di $M$ maka pernyataan-pernyataan berikut ekuivalen.

(1) Submodul pure $N$ di $M$.

(2) Submodul perkalian $N$ dan idempoten di $M$.

(3) Submodul perkalian $N$ dan $K=[N: M] K$ untuk setiap submodul $K$ di $N$.

(4) Submodul perkalian $N$ dan $[K: N] N=[K: M] N$ untuk setiap submodul $K$ di $M$.

Bukti. (1) $\Longrightarrow(2)$ Diketahui $N$ submodul pure dari $M$, berarti $I N=N \cap I M$ untuk setiap ideal $I$ di $R$.

Akan ditunjukkan $N$ submodul perkalian dan idempoten di $M$.

Misalkan $K$ submodul dari $M$ berarti $K=[K: M] M$.

Submodul $N$ disebut submodul perkalian jika $K \cap N=[K: N] N$ untuk setiap submodul $K$ di $M$. Berarti harus ditunjukkan bahwa $K \cap N \subseteq[K: N] N$ dan $[K: N] N \subseteq K \cap N$.

(1) $K \cap N \subseteq[K: N] N$

Ambil sebarang $x \in K \cap N$, artinya $x \in K$ dan $x \in N$. Karena $K$ submodul di $M$ maka $x \in[K: M] M$. Berdasarkan Teorema 3.5 jika $[K: M] \subseteq[K: N]$ maka $N \subseteq M$, maka $x \in[K: N] M$ dan $x \in[K: N] N$. Terbukti $K \cap N \subseteq[K: N] N$.

(2) $[K: N] N \subseteq K \cap N$

Ambil sebarang $x \in[K: N] N$ artinya $x=r n$, dengan $r \in[K: N]$ dan $n \in N$. Karena $r \in[K: N]$ berarti $r N \subseteq K$ atau $r n=k$, untuk suatu $n \in N$ dan $k \in K$.

Selanjutnya, $x=r n=k$ sehingga $x \in K$. Berdasarkan teorema submodul [7] diperoleh $x=r n \in N$. Karena $x \in K$ dan $x \in N$ maka $x \in K \cap N$.

Karena $K \cap N \subseteq[K: N] N$ dan $[K: N] N \subseteq K \cap N$ maka $K \cap N=[K: N] N$ atau dapat dikatakan bahwa $N$ merupakan submodul perkalian di $M$.

Selanjutnya akan ditunjukkan bahwa submodul $N$ idempotent di $M$ yaitu $N=[N: M] N$. Berarti harus ditunjukkan bahwa $N \subseteq[N: M] N$ dan $[N: M] N \subseteq N$

(1) $N \subseteq[N: M] N$

Ambil sebarang $x \in N$. Karena $N$ submodul pure maka untuk setiap ideal $I$ berlaku

$$
I N=N \cap I M=N \cap N=N
$$

Karena $x \in N=I N$ diperoleh $x \in I N$. Selanjutnya, $I \subseteq[N: M]$ berarti $x \in[N$ : $M] N$. Jadi, $N \subseteq[N: M] N$.

(2) $[N: M] N \subseteq N$

Ambil sebarang $x \in[N: M] N$ berarti $x=r n$, dengan $r \in[N: M]$ dan $n \in N$. Karena $r \in[N: M] \subseteq I \subseteq R$ berarti $r \in R$. Berdasarkan teorema submodul [7] diperoleh $x=r n \in N$. Jadi, $[N: M] N \subseteq N$.

Karena $N \subseteq[N: M] N$ dan $[N: M] N \subseteq N$ diperoleh $N=[N: M] N$ atau dapat dikatakan bahwa $N$ idempotent di $M$.

(2) $\Longrightarrow(3)$ Diketahui $N$ submodul perkalian dan $N$ idempoten di $M$ berarti $N=[N: M] N$. Akan ditunjukkan bahwa $K=[N: M] K$ untuk setiap submodul $K$ dari $N$. Berarti harus ditunjukkan bahwa $K \subseteq[N: M] K$ dan $[N: M] K \subseteq K$. Misalkan $K$ submodul di $N$ berarti $K=[K: N] N$. 
(1) $K \subseteq[N: M] K$

Ambil sebarang $x \in K$. Akan ditunjukkan $x \in[N: M] K$.

$$
\begin{aligned}
x \in K & =[K: N] N & & (\text { karena } K \text { submodul di } M) \\
& =[K: N][N: M] N & & \text { karena } N \text { idempotent di } M) \\
& =[N: M][K: N] N & & \text { karena } R \text { ring komutatif) } \\
& =[N: M] K & & (\text { karena } K \text { submodul di } N)
\end{aligned}
$$

Sehingga diperoleh $x \in[N: M] K$. Jadi, $K \subseteq[N: M] K$.

(2) $[N: M] K \subseteq K$

Ambil sebarang $x \in[N: M] K$. Akan ditunjukkan $x \in K$.

$$
\begin{aligned}
x \in[N: M] K & =[N: M][K: N] N & & \text { (karena } K \text { submodul di } N) \\
& =[K: N][N: M] N & & \text { (karena } R \text { ring komutatif }) \\
& =[K: N] N & & \text { (karena } N \text { idempotent di } M) \\
& =K & & \text { karena } K \text { submodul di } N)
\end{aligned}
$$

Sehingga diperoleh $x \in K$. Jadi, $[N: M] K \subseteq K$.

Karena $K \subseteq[N: M] K$ dan $[N: M] K \subseteq K$ maka $K=[N: M] K$ untuk setiap submodul $K$ dari $N$.

(3) $\Longrightarrow$ (4) Diketahui $N$ submodul perkalian dan $K=[N: M] K$ untuk setiap submodul $K$ dari $N$. Akan ditunjukkan $[K: N] N=[K: M] N$. Berarti harus ditunjukkan bahwa $[K: N] N \subseteq[K: M] N$ dan $[K: M] N \subseteq[K: N] N$. Misalkan $K$ submodul dari $M$ berarti $K=[K: M] M$.

(1) $[K: N] N \subseteq[K: M] N$

Ambil sebarang $x \in[K: N] N$. Akan ditunjukkan $x \in[K: M] N$.

$$
\begin{aligned}
x \in[K: N] N & =K \\
& =[N: M] K \\
& =[N: M][K: M] M \\
& =[K: M][N: M] M \\
& =[K: M] N
\end{aligned}
$$

Sehingga $x \in[K: M] N$. Jadi, $[K: N] N \subseteq[K: M] N$.

(2) $[K: M] N \subseteq[K: N] N$

Ambil sebarang $x \in[K: M] N$. Akan ditunjukkan $x \in[K: N] N$.

$$
\begin{aligned}
x \in[K: M] N & =[K: M][N: M] M \\
& =[N: M][K: M] M \\
& =[N: M] K \\
& =K=[K: N] N
\end{aligned}
$$

Sehingga $x \in[K: N] N$. Jadi, $[K: M] N \subseteq[K: N] N$.

Karena $[K: N] N \subseteq[K: M] N$ dan $[K: M] N \subseteq[K: N] N$ maka $[K: N] N=[K: M] N$ untuk setiap submodul $K$ dari $M$.

(4) $\Longrightarrow$ (1) Diketahui $N$ submodul perkalian, berarti $K \cap N=[K: N] N$ dan juga $[K: N] N=[K: M] N$. Akan ditunjukkan $N$ submodul pure yang berarti untuk setiap ideal $I$ di $R$ berlaku $I N=N \cap I M$. Berarti harus ditunjukkan bahwa $I N \subseteq N \cap I M$ dan $N \cap I M \subseteq I N$.

(1) $I N \subseteq N \cap I M$

Ambil sebarang $x \in I N$ berarti $x=r n$ dengan $r \in I$ dan $n \in N$. Berdasarkan aksioma submodul diperoleh $x \in N$. Karena $M$ modul perkalian maka terdapat ideal $I$ di $R$ sehingga $N=I M$, sehingga $x \in I M$. Selanjutnya, karena maka $x \in N$ dan $x \in I M$ maka $x \in N \cap I M$. 
(2) $N \cap I M \subseteq I N$

Ambil sebarang $x \in N \cap I M$ artinya $x \in N$ dan $x \in I M$. Berdasarkan aksioma submodul diperoleh untuk setiap $r \in I$ dan $n \in N$ berlaku $r n \in N$, sehingga $x$ dapat dinyatakan dengan $x=r n$ atau $x \in I N$. Terbukti $N \cap I M \subseteq I N$.

Karena $I N \subseteq N \cap I M$ dan $N \cap I M \subseteq I N$ maka $I N=N \cap I M$ atau dapat dikatakan bahwa $N$ merupakan submodul pure di $M$.

\section{Penutup}

Hasil penting atau sifat yang dapat dijadikan sebuah kesimpulan dari tulisan ini adalah syarat perlu suatu submodul $N$ di $R$-modul perkalian $M$ disebut submodul pure adalah $N$ merupakan submodul perkalian dan idempotent di $M$. Selain itu, sifat-sifat pada submodul pure dapat dijadikan dasar untuk penelitian submodul pure lemah pada modul multiplikasi.

\section{DAFTar Pustaka}

[1] Ali, M. M., Smith, D. J. 2004. Pure Submodules of Multiplication Modules. International Journal Algebra, Vol. 8, No. 14:649-653.

[2] Anderson, D. D., Fuller, K. R. 1974. Rings and Categories of Modules. Springer-Verlag.

[3] Arifin, Samsul. 2008. Skripsi Modul Perkalian. Universitas Gadjah Mada-Yogyakarta.

[4] Atani, S.,Ghaleh, S. 2006. On Comultiplication Modules. International Mathematical Forum.

[5] Heirstein, I. N. 1975. Topic in Algebra. John Wiley and Sons.

[6] Matsumura, H. 1986. Commutative Ring Theory. Cambridge University Press.

[7] Naoum, A. G, Hasan, M. A. K. 1986. The residual of finitely generated multiplication modules. Archiv der Mathematik, Vol. 46, 225-230.

[8] Wahyuni, S., Wijayanti, I. E., Palupi, D. J. E. 2013. Teori Ring dan Subring. Yogyakarta.

[9] Wijayanti, I. E., Wahyuni, S. 2013. Teori Modul. Yogyakarta.

[10] Wisbauer, R. 1991. Foundation of Module and Ring Theory. A Handbook for Study and Research. University od Du?sseldorf. 